\title{
Implementação do Balanced Scorecard de acordo com os Pre- ceitos da Gestão do Conhecimento em uma Organização que Explora a Atividade Pecuária de Gado Bovino de Corte em Minas Gerais
}

Balanced Scorecard implementation in accordance with the precepts of knowledge management in an organization that explores the activity Cattle Cattle Crop in Minas Gerais

\begin{abstract}
Alessandra Vasconcelos Gallon
Doutora em Engenharia de Produção na Universidade Federal de Santa Catarina

Professora do Mestrado em Administração e Controladoria da Universidade Federal do Ceará

Endereço: Rua Coronel Jucá, n॰ 330, Bairro Meireles, CEP: 60170-320 - Fortaleza/CE - Brasil

E-mail: alegallon@terra.com.br

Telefone: (85) 3021-3443
\end{abstract}

\section{Adriano Antonio Nuintin}

Mestre em Controladoria e Contabilidade na Universidade de São Paulo

Professor da Universidade Federal de Alfenas (UNIFAL-MG) - Campus Varginha

Endereço: Rua Coronel Storino, n॰245, Bairro Parque São José

CEP: 37030-250 - Varginha/MG - Brasil

E-mail: adriano.nuintin@unifal-mg.edu.br

Telefone: (35) 3214-4163

\section{Maria Aparecida Curi}

Mestre em Administração na Faculdade Cenecista de Varginha

Professora da Universidade Federal de Alfenas (UNIFAL-MG) - Campus Varginha

Endereço: Rua Santa Rita, n॰ 97, Bairro Catanduvas

CEP: 37006-200 - Varginha/MG - Brasil

E-mail: maria.curi@unifal-mg.edu.br

Telefone: (35) 9988-6590

\section{Leandro Rivelli Teixeira Nogueira}

Mestre em Administração na Universidade Federal de Lavras (UFLA)

Professor da Universidade Federal de Alfenas (UNIFAL-MG) - Campus Varginha

Endereço: Av. Alfredo Braga de Carvalho, n॰ 303, Parque Industrial JK

CEP: 37062-440 - Varginha/MG - Brasil

E-mail: leandro.teixeira@unifal-mg.edu.br

Telefone: (35) 3214-1761

Artigo recebido em 05/02/2010. Revisado por pares em 12/03/2010. Reformulado em 02/04/2010. Recomendado para publicação em 12/12/2010 por Sandra Rolim Ensslin (Editora Científica). Publicado em 29/10/2010. Artigo apresentado $9^{\circ}$ Congresso Internacional de Gestão de Tecnologia e Sistema de Informação (CONTESCI), 2010, São Paulo, 2010. 


\title{
Resumo
}

Este artigo objetiva apresentar a implementação do Balanced Scorecard (BSC) de acordo com os preceitos da gestão do conhecimento em uma organização que explora a atividade pecuária de gado bovino de corte em Minas Gerais. A pesquisa exploratória consiste de um estudo de caso, com abordagem qualitativa dos dados. O resultado da implementação do modelo de avaliação BSC permitiu aos gestores da organização rural conhecer a situação atual, identificar pontos de desvios e definir ações corretivas, buscando, com isso, atingir seus objetivos, estratégias e sua visão com vistas a cumprir sua missão, proporcionando a criação e gestão do conhecimento organizacional.

Palavras-chave: Balanced Scorecard (BSC). Gestão do conhecimento. Modelo de avaliação. Tomada de decisão. Organização rural.

\begin{abstract}
This article presents the implementation of the Balanced Scorecard (BSC) in accordance with the precepts of knowledge management in an organization that explores the ranching of cattle beef cattle in Minas Gerais. Exploratory research is a case study approach with qualitative data. The result of implementing the BSC assessment model allowed the managers of rural organization know the current situation, identify points of diversion and define corrective actions, seeking thereby achieve its objectives, strategies and vision in order to fulfill its mission, providing the establishment and management of organizational knowledge.
\end{abstract}

Key words: Balanced Scorecard (BSC). Knowledge management. Evaluation model. Decision making. Rural organization.

\section{Introdução}

Em um mercado cada vez mais concorrido, onde preços e qualidade dos produtos são semelhantes, manter-se competitivo torna-se cada vez mais difícil. Tais necessidades e características fazem com que as organizações avaliem constantemente seu desempenho e gerenciem o conhecimento organizacional para continuarem atuantes no mercado.

Para Kardec, Arcuri e Cabral (2005) avaliar é perceber a realidade da organização e fazer uma análise crítica. A informação gerada pela avaliação deve ser passada em uma linguagem adequada para o seu entendimento. Ainda de acordo com esses autores, a avaliação de desempenho pode ser efetuada por meio de indicadores que mostram a situação em que a empresa se encontra e sua evolução ao longo do tempo. Os indicadores permitem medir o resultado das ações tomadas, bem como medir os desvios entre o planejado e o realizado (KARDEC; FLORES; SEIXAS, 2005).

Conforme Figueiredo e Caggiano (2004) a avaliação de desempenho tem como objetivos: (i) calcular a eficiência das responsabilidades assumidas pelos gestores e como têm sido desempenhadas; (ii) identificar as ações corretivas que devem ser implementadas; (iii) possibilitar a averiguação da motivação dos gestores no cumprimento das atividades relacionadas aos objetivos da organização; 
(iv) comparar os diferentes setores da organização; e (v) descobrir quais áreas da organização demandam ações de melhoria.

Até os anos 50, o desempenho empresarial estava ligado essencialmente à capacidade da organização em maximizar lucros sem se preocupar com qualquer outro critério (SCHMIDT; SANTOS; MARTINS, 2006). Por sua vez, diante da importância desse tema para os dias atuais, Kaplan e Norton (1997) enfatizam a necessidade de incorporar aos modelos de indicadores financeiros tradicionais outros indicadores não-financeiros, como satisfação dos clientes, retenção dos clientes, motivação dos funcionários, dentre outros.

Nesse contexto, surge o Balanced Scorecard (BSC) como um modelo de avaliação que busca incorporar os indicadores não-financeiros, e com isso melhorar a avaliação de desempenho das organizações. Kaplan e Norton (1997), seus idealizadores, asseguram que este sistema tem como diferencial o fato de incorporar indicadores financeiros e não-financeiros, de tal forma a traduzir a estratégia da organização em medidas tangíveis.

No BSC a missão e a estratégia da empresa são traduzidas em um conjunto de medidas de desempenho. Os indicadores financeiros do BSC permitem conhecer o resultado das decisões passadas, completando-os com indicadores operacionais, ligados à satisfação dos clientes, aos processos internos e à capacidade da organização de aprender e melhorar.

De acordo com Shimizu (2006), o processo de decisão para definir quais ações são necessárias para manter ou corrigir uma situação identificada, pode ser visualizado em quatro etapas: (i) percepção da necessidade de decisão; (ii) formulação das alternativas de ação; (iii) avaliação das alternativas; e (iv) escolha de uma ou mais alternativas para fins de execução. Um dos fatores que podem contribuir para o sucesso do processo decisório é a especialização, ou seja, cada tomada de decisão deve estar baseada em conhecimentos profundos de um especialista (SHIMIZU, 2006).

As organizações tomam decisões com base em experiências passadas e com base no conhecimento acumulado durante sua existência. Sob esse aspecto, é necessário gerir e disseminar esse conhecimento na organização para transformar informações ou experiências isoladas em algo que toda a organização possa utilizar para o seu desenvolvimento.

Nesse cenário, surge a seguinte pergunta de pesquisa: Quais os resultados da implementação do Balanced Scorecard (BSC) em uma organização rural de acordo com os preceitos da gestão do conhecimento? Tal questionamento atende a proposição do problema central da pesquisa, qual seja, buscar salientar a contribuição da gestão do conhecimento tácito e explícito acumulados pela organização, no processo de implementação do BSC e no processo decisório em uma organização rural, para manter ou melhorar a situação evidenciada por seus indicadores. 
Nesse sentido, o objetivo deste estudo é apresentar a implementação do Balanced Scorecard (BSC) de acordo com os preceitos da gestão do conhecimento em uma organização que explora a atividade pecuária de gado bovino de corte em Minas Gerais.

Tendo em vista a importância de se estudar a gestão do conhecimento e o processo de tomada de decisão, este trabalho justifica-se na medida em que buscará concentrar esforços na geração de conhecimento relacionado ao suporte informacional no processo decisório em uma organização rural (atividade com poucos estudos empíricos relacionados ao tema estudado), proporcionando subsídios para estudos futuros.

O artigo está estruturado da seguinte forma: inicialmente é apresentada a introdução seguida do referencial teórico, no qual são abordados avaliação de desempenho, tomada de decisão e Balanced Scorecard, e gestão do conhecimento; a seguir, apresenta-se o enquadramento e os procedimentos metodológicos da pesquisa, no qual se propõe um macro processo de implementação do BSC e apoio à decisão, na sequência, apresenta-se o estudo de caso desenvolvido em uma organização rural; e encerra-se com as considerações finais.

\section{Referencial Teórico}

Os três eixos teóricos que informam o presente estudo são explorados, em termos de revisão de literatura, nas subseções a seguir.

\subsection{Avaliação de Desempenho e o Processo de Tomada de Decisão}

$\mathrm{Na}$ era do conhecimento, foram criadas muitas medidas de planejamento e controle, e está inserida nessas medidas a avaliação de desempenho, que de maneira geral afeta significativamente o comportamento de todos os envolvidos nos múltiplos processos dentro de uma organização (LIMA, 2009; DUTRA, 2005).

De acordo com Pereira (2001) avaliar é o exercício de análise e do julgamento sobre qualquer situação que exija uma apreciação dos fatos, idéias, objetivos e, também, uma tomada de decisão a fim de se atingir uma situação desejada. $\mathrm{O}$ autor ainda menciona que avaliação significa o ato de atribuir valor, seja qualitativo (importância) ou quantitativo (mensuração) e desempenho entende-se pela realização de uma ou um conjunto de atividades (PEREIRA, 2001).

Para Miranda e Silva (2002) três aspectos devem ser analisados no processo de avaliação de desempenho: Por que medir? O que medir? Como medir? O "por que medir" é respondido com a necessidade de as organizações acompanharem e saberem se as suas ações implementadas estão de acordo com a missão, pois não é possível controlar se não é possível medir. É definindo com essa pergunta qual o 
objetivo da informação gerada com a avaliação, no sentido de auxiliar os usuários na tomada de decisão. Já o "o que medir" está relacionado com a verificação da realização de um objetivo ou meta, da estratégia e da missão. A avaliação do desempenho proporciona conhecer quem contribuiu para atingir os objetivos, quando atingiu as metas, quais as principais dificuldades, e quais as falhas que ocorreram no processo decisório. É definido o objeto de avaliação. Enquanto que o "como medir" refere-se à definição do conjunto de indicadores que irão operacionalizar a avaliação de desempenho, ou seja, os indicadores que serão usados no sistema de diagnóstico do processo decisório organizacional.

Nessa perspectiva, os indicadores são uma forma de medir uma situação atual contra um padrão previamente estabelecido. Os indicadores dão suporte à análise crítica dos resultados, às tomadas de decisão e ao planejamento e controle dos processos da organização (NUINTIN, 2007).

Conforme Nascimento et al. (2008), no contexto atual e devido à complexidade da administração empresarial, é essencial que os gestores disponham de informações que permitam determinar a ordem de prioridade de consumo dos recursos (físicos, financeiros, humanos, tecnológicos, etc.) da empresa, tendo em vista o alcance de seus objetivos estratégicos.

Por conta disso, a medição de desempenho cada vez mais se torna parte fundamental da gestão organizacional, já que a avaliação do desempenho permite aos gestores conhecer a real situação da organização em relação aos objetivos estabelecidos, além de permitir conhecer os desvios tanto quantitativos como qualitativos, subsidiando os gestores no processo decisório (DUTRA et al, 2009).

Santos e Ponte (1998) definem decisão como o ato de escolher uma dentre várias opções com o objetivo de resolver um problema ou responder a alguma oportunidade. Ainda conforme os autores, o processo decisório pode ser definido como o conjunto de etapas ou fases seguidas pelo decisor para efetuar a escolha da alternativa de ação, assim descritas:

1) caracterização da necessidade de decisão: fase de definição do objeto da decisão, que é o próprio problema a ser resolvido;

2) definição do objetivo: etapa na qual o decisor define exatamente os fins a que deseja atingir;

3) definição e obtenção de informações relevantes: etapa de definição e obtenção de informações sobre as variáveis que devem ser consideradas no processo de tomada de decisão;

4) formulação das alternativas: são formuladas as diversas opções de ação que solucionam o problema;

5) avaliação das alternativas: são mensuradas e avaliadas as consequências derivadas das várias alternativas de ação que configuram as diversas hipóteses de solução do problema;

6) escolha da alternativa: com base na avaliação das conseqüências das 
alternativas estudadas, seleciona-se aquela que seja mais adequada como solução do problema para que o objetivo definido seja alcançado.

Para que o processo decisório consiga atingir seu objetivo, o tomador de decisão ou os tomadores de decisão utilizam-se do conhecimento tácito e ou explícito, adquirido e acumulado pela organização, para a escolha da melhor ou melhores alternativas após conhecida a situação evidenciada pelos indicadores dos modelos de avaliação de desempenho.

$\mathrm{O}$ conhecimento acumulado quando lembrados e utilizados em futuras decisões fornece informações que diminuem o custo das transações, aprimoram a tomada de decisões e podem se tornar um diferencial competitivo (SCHARF; SORIANO-SIERRA, 2008).

No que se refere à avaliação de desempenho como suporte ao processo de tomada de decisão, pode-se identificar na literatura a existência de modelos gerenciais com diversas formulações e interpretações. Neste trabalho, o modelo a ser estudado é o Balanced Scorecard (BSC), desenvolvido por Kaplan e Norton, constituindo uma ferramenta para a avaliação de desempenho das organizações.

\subsection{Balanced Scorecard (BSC) e os Mapas Estratégicos}

Para Kaplan e Norton (2000), foi através do BSC que as primeiras organizações focalizaram e alinharam suas equipes executivas, unidades de negócio, recursos humanos, tecnologia da informação e recursos financeiros à estratégia da organização.

Com isso, tornou-se possível observar a atuação das organizações baseando-se em cinco princípios comuns. Estes princípios foram considerados por Kaplan e Norton (2000) como sendo os princípios da organização focalizada na estratégia, sendo: a) traduzir a estratégia em termos operacionais; b) alinhar a organização à estratégia; c) transformar a estratégia em tarefa de todos; d) converter a estratégia em processo contínuo; e) mobilizar a mudança por meio da liderança.

No entanto, segundo Mosimann e Fischer (1999), para que os resultados globais da empresa possam ser maximizados, é necessária a existência de um órgão na estrutura empresarial, para administrar o sistema e informações econômicofinanceiras da empresa e coordenar os esforços dos gestores de cada área.

Ainda objetivando a maximização dos resultados, Kaplan e Norton (1997), defendem que o BSC deve contar a história da estratégia, começando pelos objetivos financeiros de longo prazo e relacionando-os depois à sequência de ações que precisam ser tomadas relacionadas aos processos financeiros, dos clientes, dos processos internos e, por fim, dos funcionários e sistemas.

Dessa forma, os indicadores financeiros e não-financeiros propostos no 
BSC são agrupados em quatro perspectivas, que estabelecem um diálogo entre os formuladores da estratégia e os stakeholders da organização. Assim, segundo Herrero Filho (2005), no BSC são identificadas as atividades críticas que geram valor para os acionistas, clientes, colaboradores, fornecedores e para a comunidade,

As quatro perspectivas compõem a estrutura do BSC, conforme pode ser visto na Figura 1, abaixo. Através de objetivos, medidas (ou indicadores), metas, e iniciativas, o BSC busca traduzir a visão e a estratégia da empresa sob a ótica dessas perspectivas.

Figura 1: Estrutura do Balanced Scorecard

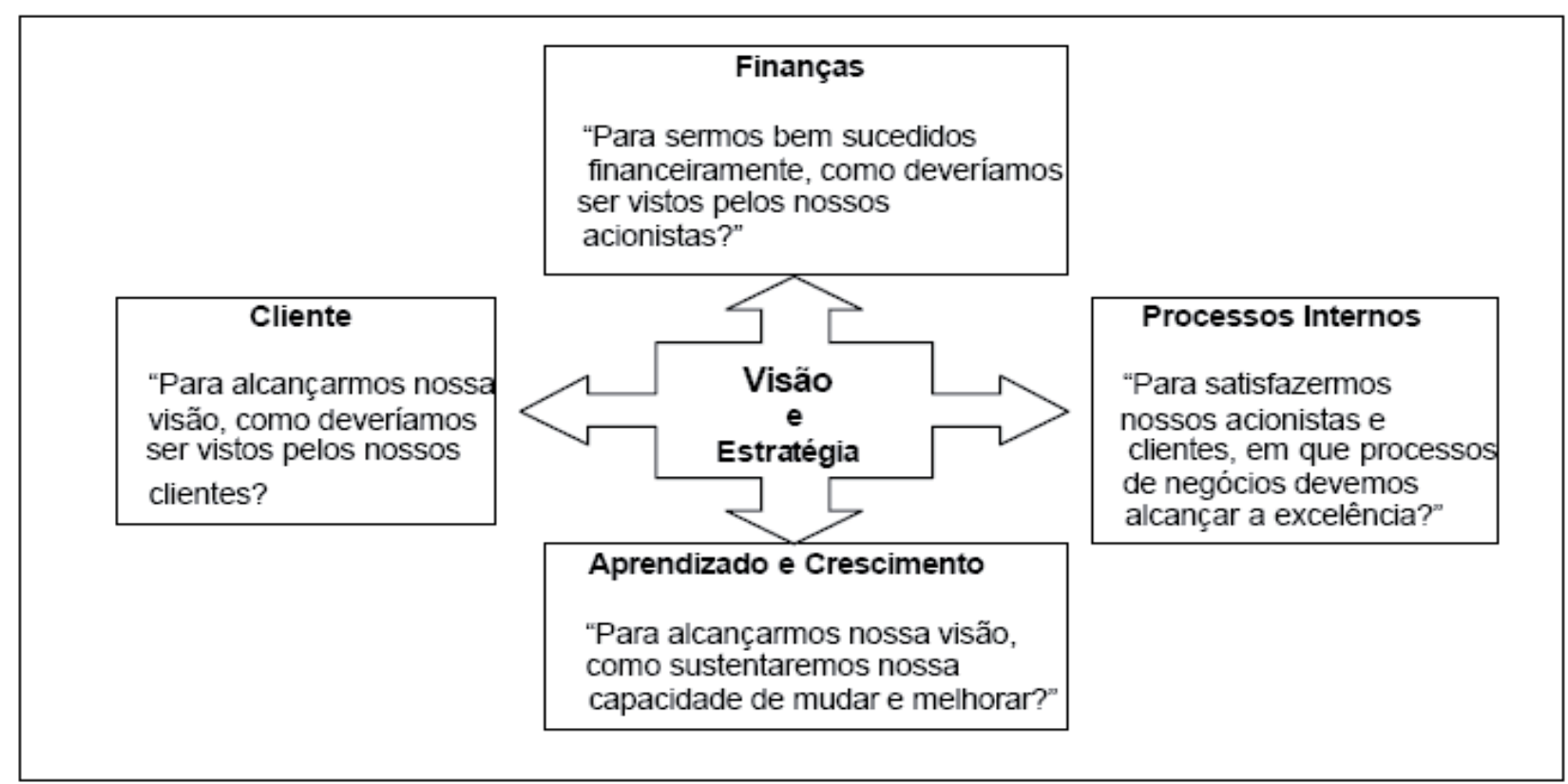

Fonte: Kaplan e Norton (1997, p. 10).

Na seqüência, apresenta-se separadamente cada uma das perspectivas, conforme Kaplan e Norton (1999), objetivando melhor entendimento.

- Perspectiva financeira - as medidas financeiras de desempenho indicam se a estratégia de uma empresa, sua implementação e execução estão contribuindo para a melhoria dos resultados financeiros;

- Perspectiva dos clientes - essa perspectiva permite que os executivos identifiquem os segmentos de clientes e mercados, nos quais a empresa pode competir, além das medidas do desempenho da unidade nesses segmentos alvo;

- Perspectiva dos processos internos - os objetivos dos processos internos no BSC destacam os processos, dos quais vários talvez não estejam sendo executados atualmente, que são absolutamente críticos para o sucesso da estratégia;

- Perspectiva do aprendizado e crescimento - essa perspectiva objetiva identificar a infra-estrutura necessária que resulta em crescimento e melhoria, através de investimento nos colaboradores, 
no aperfeiçoamento da tecnologia da informação e dos sistemas e no alinhamento dos procedimentos e rotinas organizacionais.

Ainda de acordo com seus idealizadores, no BSC, os objetivos financeiros, do cliente e dos processos internos geralmente apresentam lacunas entre as capacidades atuais das pessoas, dos sistemas e dos procedimentos, e o que será necessário para alcançar um novo desempenho (KAPLAN; NORTON, 1997). Com isso, a perspectiva do aprendizado e crescimento muitas vezes tem que sofrer modificações para que possam ocorrer os resultados positivos nas demais perspectivas.

De acordo com Kaplan e Norton (2004), os mapas estratégicos fornecem ferramentas para comunicar as estratégias, processos e sistemas que auxiliarão a implementar a estratégia da organização, além de mostrar as relações de causa e efeito, representadas nas quatro perspectivas, pelas quais certas decisões produzem os resultados almejados.

O mapa demonstra como o trabalho e as atividades estão alinhadas com os objetivos principais da organização. A divulgação da estratégia, das metas e a relação de causas/efeitos nas quatro perspectivas do BSC, orientam o desempenho da organização e cria caminhos para conversão de iniciativas e recursos em melhores resultados.

A construção do mapa estratégico começa, geralmente, com a estratégia financeira que aumentará o valor para os acionistas (KAPLAN; NORTON, 2004).

$\mathrm{Na}$ perspectiva financeira encontram-se duas estratégias para aumentar o valor para os acionistas: crescimento da receita e aumento da produtividade. Para a organização diferenciar-se dos concorrentes, atraindo, retendo e aprofudando o relacionamento com seus clientes, a perspectiva do cliente apresenta três diferenciadores: excelência operacional, intimidade com o cliente e liderança do produto.

Na perspectiva dos processos internos são identificadas as atividades pelas quais proporcionarão a diferenciação da organização do ponto de vista do cliente, bem como aumentar a produtividade e alcançar os objetivos financeiros.

Conforme Kaplan e Norton (2004), o fundamento do mapa estratégico é a perspectiva de aprendizado e crescimento, pois, define as competências e habilidades essenciais, as tecnologias e a cultura organizacional necessárias para suportar a estratégia de negócios da organização.

Com base na Figura 2 são demonstradas as etapas para a elaboração do mapa estratégico. 


\section{Figura 2: Modelo para elaboração do Mapa Estratégico}

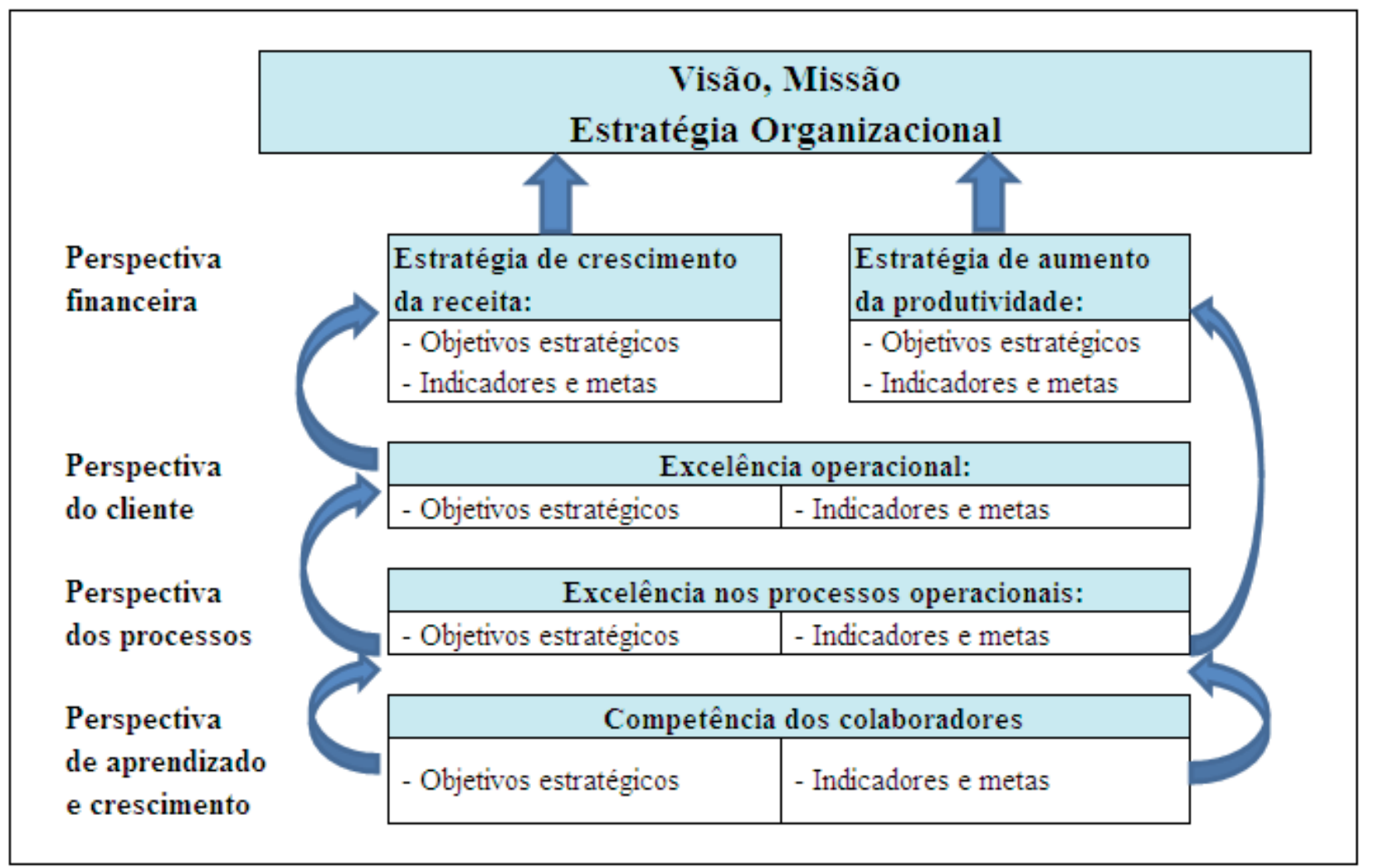

Fonte: Elaborado pelos autores, adaptado de Kaplan e Norton (1997).

De acordo com a Figura 2 verifica-se que as etapas para a elaboração do mapa estratégico são:

1) identificar a visão e a missão da organização. A visão evidencia a posição na qual a organização quer estar no futuro, a missão informa a razão de existir da organização;

2) definir a estratégia para o cumprimento da visão e missão identificadas;

3) identificar os objetivos estratégicos para cada perspectiva do BSC, a partir da estratégia definida;

4) eleger os indicadores para cada objetivo estratégico e definir as respectivas metas.

Diante do exposto, o mapa estratégico possibilita que os integrantes do processo decisório compreendam e melhorem seu entendimento sobre o negócio da organização, e permite, também, aumentar a percepção de como seu trabalho está integrado à estratégia da organização. Dessa forma, o conhecimento organizacional, especialmente o conhecimento dos seus integrantes são fundamentais para a implementação do BSC e para as decisões que contribuirão para atingir os objetivos e estratégias da organização. 


\subsection{Gestão do Conhecimento}

É comum existir por parte das organizações uma dificuldade de reconhecer as diferenças e o correto significado entre os termos: dado, informação e conhecimento. Essa deficiência pode gerar grandes esforços com iniciativas de tecnologia que dificilmente produzirão resultados positivos ou satisfatórios.

Entender as diferenças entre dado, informação e conhecimento é primordial para se conseguir realizar um trabalho relacionado ao conhecimento. Uma breve explanação sobre esses três elementos é fundamental para compreender melhor os fatores envolvidos na transformação de dados em informação e de informação em conhecimento (DAVENPORT; PRUSAK, 1998).

Dado é o registro puro, ainda não interpretado, analisado e processado, por si só não conduz a uma compreensão de determinado fato ou situação. A informação é o dado que foi processado e armazenado de forma compreensível, pronto para ser utilizado pelos gestores, em suas decisões. Já o conhecimento consiste na conclusão tirada dos dados e informações, ou seja, o conhecimento deriva da informação da mesma forma que a informação deriva dos dados (OLIVEIRA; PEREZ JR.; SILVA, 2005). Em outras palavras, o conhecimento é o resultado do processamento de informações e do aproveitamento dos insights subjetivos dos colaboradores das organizações (TERRA, 2000).

Por sua vez, de acordo com Terra (2000), encontra-se na literatura vários tipos de conhecimento nas organizações, dentre eles o tácito ou implícito e o conhecimento explícito. O explícito é reconhecido como conhecimento útil, podendo ser formalizado, sistematizado e facilmente comunicável em forma de procedimentos, representados em documentos, livros, arquivos e banco de dados. Já o conhecimento tácito é pessoal e subjetivo incorporado à experiência individual ao longo do tempo e exige um intenso contato pessoal para ser compartilhado (MUSSI; ANGELONI, 2008).

Assim, para se entender melhor o que é o conhecimento nas organizações, uma definição funcional é apresentada por Davenport e Prusak (1998) como sendo uma mistura de experiências, valores, informações e insight, que proporciona uma estrutura para avaliação e incorporação de novas experiências e informações. $\mathrm{O}$ conhecimento tem origem na mente dos conhecedores. Nas organizações, normalmente, está embutido não só em documentos ou repositórios, mas também em rotinas, processos, práticas e normas organizacionais.

Segundo Terra (2000) a gestão do conhecimento tem um caráter universal, ou seja, aplica-se a qualquer tipo de organização e os desafios que estão relacionados à sua efetivação requerem a criação de uma nova infraestrutura organizacional, significativos esforços de conscientização e de comunicação, ativa participação pessoal da alta administração e de incentivo individual e coletivo. A 
gestão do conhecimento nas organizações passa, necessariamente, pela compreensão das características e demandas do ambiente competitivo e, também, pelo entendimento das necessidades individuais e coletivas associadas aos processos de criação e aprendizado.

Para o desenvolvimento do processo de aprendizagem dentro de uma organização, é necessário estruturar uma maneira sistemática de adquirir, criar, captar, armazenar, gerenciar, utilizar e transmitir o conhecimento. A gestão do conhecimento passa a ser a responsável por garantir que o processo de aprendizagem seja contínuo e permanente (FIATES, 2008).

Nesse sentido, é necessário assegurar instrumentos e modelos que possam orientar as organizações a utilizar e valorizar o conhecimento como um importante recurso estratégico. Para Terra (2000) as organizações criadoras de conhecimento são aquelas que criam, sistematicamente, novos conhecimentos, disseminam pela organização inteira e, rapidamente, os incorporam a novas tecnologias e produtos. Isso ocorre a partir da interação entre conhecimento tácito e explícito, a qual é conhecida como conversão do conhecimento.

Nokata e Takeuchi (1997) apresentam quatro processos de conversão do conhecimento: socialização (tácito para tácito), externalização (tácito para explícito), internalização (explícito para tácito) e combinação (explícito para explícito). A socialização corresponde à troca de conhecimento tácito entre indivíduos, é o processo pelo qual experiências são trocadas. Pode ser evidenciada nas organizações como treinamentos, sessões informais, brainstormings, interações com os clientes, workshops. A externalização facilita a comunicação dos conhecimentos tácitos, normalmente difíceis de verbalização, utilizando metáforas, analogias, conceitos, hipóteses e modelos. Já a internalização ajuda a vivenciar operacionalmente as experiências dos outros. A conversão do conhecimento explícito em tácito pode se realizar sob a forma de documentos, manuais, vídeos institucionais. Por sua vez, o processo de combinação refere-se à troca de diferentes conhecimentos explícitos para gerar um novo conhecimento explícito. Podendo ocorrer, por meio de documentos, reuniões, redes de computador.

Ainda com relação à gestão do conhecimento, Goulart (2008) lembra que mapear os conhecimentos, identificar quem os possui e como é possível compartilhar, gerando assim, outros conhecimentos, em um ciclo de aprendizado prático e contínuo é uma ação a ser realizada pelas organizações que desejam construir vantagens competitivas sustentáveis.

Dessa forma, o conhecimento deve ser revertido em produtividade, qualidade e soluções inovadoras para contribuir no processo decisório das organizações e se constituir em um diferencial de competitividade.

\section{Enquadramento e Procedimentos Metodológicos}


Os delineamentos desta pesquisa deram-se em função dos objetivos, dos procedimentos e da abordagem do problema. No que concerne aos objetivos, esta pesquisa consiste de um estudo do tipo exploratório, que para Cervo e Bervian (1996), é responsável por observar, registrar, analisar e correlacionar os fatos ou fenômenos sem manipulá-los.

A estratégia de pesquisa utilizada é a de estudo de caso. Conforme definição de Yin (2005, p. 33), este tipo de investigação "enfrenta uma situação tecnicamente única em que haverá muito mais variáveis de interesse do que pontos de dados"; o resultado desse tipo de pesquisa baseia-se em várias fontes de evidências e se beneficia do desenvolvimento prévio de proposições teóricas para conduzir a coleta e a análise de dados (YIN, 2005).

O estudo de caso foi intensivo em uma organização rural, compreendendo fenômenos sociais complexos, cuja denominação social declina-se revelar por motivos de sigilo. A organização rural estudada está localizada no estado do Mato Grosso do Sul, com uma área de 2.221 hectares de pastagens e 3.329 cabeças de animais, sendo objetivo desta organização a criação do gado de corte. Ressaltase que a organização rural objeto desta investigação não dispõe até o momento de ferramentas sistematizadas para medição de desempenho e gestão estratégica organizacional.

Os dados foram coletados na empresa de duas formas. A primeira fonte de dados teve natureza secundária (documentos gerenciais e relatórios contábeis). Os demonstrativos contábeis (Balanço Patrimonial, Demonstração do Resultado do Exercício e Demonstração de Fluxo de Caixa) foram utilizados para identificar as principais Despesas e Custos, o Faturamento e os Resultados dos Exercícios anteriores da organização rural importantes para definição dos indicadores. Dos relatórios gerenciais foram retiradas informações que possibilitaram a identificação dos indicadores mais especificamente relacionados à perspectiva do cliente, dos processos internos e do aprendizado e crescimento. O passo seguinte foi confrontar as informações capturadas na análise documental (informações coletadas nos relatórios gerenciais e demonstrativos contábeis), com a participação de três reuniões conduzidas por meio de técnicas de brainstorming (fonte primária) com os responsáveis pela gestão da organização (o administrador e o sócio-proprietário).

$\mathrm{Na}$ análise dos dados, utilizou-se a abordagem qualitativa. Richardson (1999, p. 39) explica que "as investigações que se voltam para uma análise qualitativa têm como objeto situações complexas ou estritamente particulares".

O processo de determinação dos objetivos estratégicos e da escolha dos indicadores para realização e avaliação da estratégia organizacional, envolveu os gestores e os responsáveis das áreas financeira, comercial, produtiva e recursos humanos. A implementação do BSC ficou sob a responsabilidade de um coordena- 
dor. Para isso, com reuniões semanais, as etapas do processo de implementação do BSC eram apresentadas, discutidas e executadas de acordo com um cronograma de atividades distribuídas conforme a função e o conhecimento tácito individual.

Para o cálculo dos indicadores foram levantados dados financeiros, econômicos, operacionais e de mercado do ano de 2009.

Destaca-se que os indicadores de desempenho foram construídos a partir da existência e disponibilidade de aspectos objetivos de mensuração, ou seja, privilegiaram-se os instrumentos formais de medição como recurso para obtenção de informações requeridas para elaboração do painel de avaliação de desempenho da organização.

No que se refere aos procedimentos metodológicos, de acordo com a análise do referencial teórico, e com o objetivo do trabalho, elaborou-se um macro processo de implementação do BSC para apoio à decisão, demonstrado por um fluxograma, relacionando o processo de gestão do conhecimento, o processo de implementação do BSC e o processo de tomada de decisão.

Para a elaboração do macro processo foram consideradas as seguintes definições constitutivas:

1) Gestão do conhecimento: processo de aquisição, criação, disseminação e utilização do conhecimento tácito e explícito, individual e organizacional para a tomada de decisão;

2) Tomada de decisão: processo de identificação do problema, busca de informações, determinação de alternativas, avaliação das alternativas e escolha das alternativas para a avaliação, manutenção e melhoria do desempenho organizacional;

3) Implementação do BSC: processo de identificação da visão e da missão, definição da estratégia organizacional, definição dos objetivos estratégicos, determinação dos indicadores da avaliação e estabelecimento de metas a serem atingidas.

Por meio das informações disponibilizadas na Figura 3, observa-se que o macro processo de implementação do BSC e decisão inicia-se demonstrando o conhecimento adquirido e criado, acumulado e gerenciado pela organização durante sua permanência no mercado.

O conhecimento gerado a partir do fluxograma do macro processo deve ser disseminado e utilizado para dar suporte ao processo de implementação do BSC na organização, auxiliando na identificação da visão e missão, definição da estratégia organizacional e definição dos indicadores de acordo com as quatro perspectivas do modelo de avaliação.

A Figura 3 apresenta o fluxograma do macro processo de implementação do BSC para apoio à decisão. 
Figura 3: Macro processo de implementação do BSC para apoio à decisão

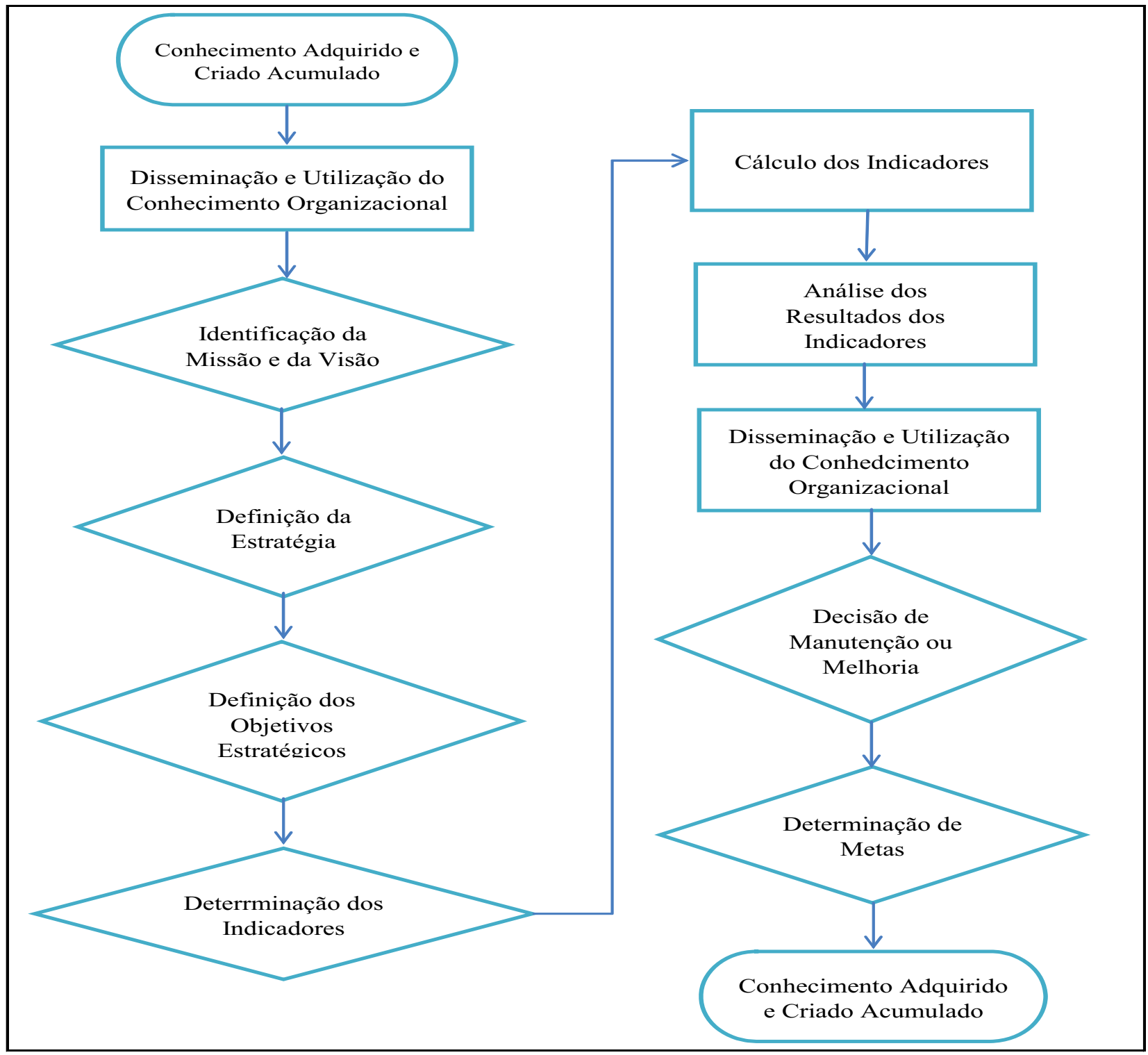

Fonte: Elaborada pelos autores.

Para a definição da estratégia ou ações para o cumprimento da visão e da missão é necessário a utilização do conhecimento acumulado da organização e dos gestores chaves da mesma. Para a definição dos objetivos estratégicos e dos indicadores para cada perspectiva do BSC é fundamental a participação, no mínimo, dos responsáveis das áreas financeira, comercial, processos produtivos e de pessoal, possibilitando dessa forma identificar possíveis alternativas e pontos críticos a serem avaliados para cumprir a estratégia organizacional.

Essa disseminação e conversão do conhecimento tácito em explícito ou explícito em tácito podem ocorrer por meio de reuniões, treinamentos, brainstormings, documentos, manuais, vídeos institucionais, trocas de experiências.

Evidenciado a situação atual, conforme os resultados dos indicadores, 
inicia-se o processo de tomada de decisão buscando informações internas e externas, determinando alternativas de possíveis soluções, avaliando as alternativas e é feito a escolha das alternativas para manter ou melhorar os resultados, bem como a determinação de metas a serem atingidas para cada perspectiva do BSC.

$\mathrm{O}$ macro processo termina demonstrando a aquisição e criação do conhecimento organizacional, ampliado e melhorado, após a execução das etapas descritas. De acordo com o macro processo proposto às próximas etapas são o cálculo dos indicadores e análise dos resultados evidenciados pelos mesmos (apresentadas na seção 4 - Estudo de Caso).

Dessa forma, o fluxograma mostra que a gestão conhecimento é um processo dinâmico pelo o qual a realização das atividades e decisões retoma o conhecimento e gera novos conhecimentos, devido às novas situações, contribuindo para o aprendizado constante dos indivíduos e para a organização como um todo.

\section{Estudo de Caso}

Para atingir o objetivo do trabalho foi feito um estudo em uma organização rural estabelecida em Mato Grosso do Sul que explora a atividade agropecuária, mais especificamente a produção de gado bovino de corte.

$\mathrm{O}$ agronegócio não se restringe à atividade agrícola, pecuária ou rural. $\mathrm{O}$ agronegócio contempla todas as operações que envolvem a produção e distribuição dos insumos rurais, as operações de produção, armazenamento, distribuição e o atendimento aos consumidores (PEREIRA, 1996). Araujo (2005) salienta a importância de compreender o agronegócio, por todos os tomadores de decisão, dentro de uma visão sistêmica. Essa visão sistêmica permite compreender que o agronegócio engloba os setores denominados "antes da porteira" ou "a montante da produção agropecuária", "dentro da porteira" ou "produção agropecuária" e "após a porteira" ou "a jusante da produção agropecuária".

A produção agropecuária possui algumas especificações que a diferenciam da produção de outros bens manufaturados, as quais devem ser consideradas na tomada de decisão. Araujo (2005) cita três especificações: a sazonalidade da produção, a influência de fatores biológicos e perecibilidade rápida.

Dentre as atividades do agronegócio encontra-se a atividade pecuária de corte, objeto de estudo deste trabalho. A atividade pecuária que pode ser definida, conforme Santos, Marion e Segatti (2002), como a arte de criar e tratar o gado. A pecuária trata dos animais criados para abate, consumo doméstico, serviços na lavoura, reprodução, leite, para fins industriais e comerciais.

No processo de produção pecuária existem três sistemas de produção: a pecuária extensiva, a intensiva e a semi-intensiva. De acordo com 
Santos, Marion e Segatti (2002), no sistema extensivo, os animais são mantidos em grandes áreas de pastos nativos, sem alimentação suplementar. No sistema intensivo, há um aumento do número de animais em uma pequena área com o objetivo de ganho de peso e aprimoramento técnico. E por meio do sistema semiintensivo se consegue alta produtividade, mantendo o gado no pasto (orgânico), com adubação constante e implantação de cerca elétrica.

A Empresa Brasileira de Pesquisa Agropecuária (EMBRAPA, 2005), caracterizou a cadeia produtiva da pecuária de corte como uma atividade que engloba as fases de cria, recria e engorda e utiliza diferentes níveis tecnológicos e uma gama variada de insumos.

A fase de cria envolve a produção de bezerros. $\mathrm{O}$ animal considerado bezerro possui idade de até dezoito meses com peso entre quatro e oito arrobas. A fase de recria compreende desde a desmama até o ponto em que a fêmea inicia seu período produtivo e em que o macho inicia a fase de engorda. E a fase de engorda tem por objetivo aumentar o peso do animal para futura comercialização (LIMA, 2005).

Para melhor entendimento e desenvolvimento do trabalho define-se a seguir as seguintes terminologias: unidades animais; índices de desempenho animal e rentabilidade.

As unidades animais (U.A.) são índices utilizados com o objetivo de proporcionalização de animais devido às diferentes categorias ou espécies, a tabela 1 demonstra a tabela de índice de conversão por categoria de animal.

Tabela 1: Unidade animal

\begin{tabular}{l|l}
\hline Touros adultos & 1,20 \\
\hline Vacas adultas & 1,00 \\
\hline Novilhos(as) de 3 ou + anos & 1,00 \\
\hline Novilhos(as) de 2 anos & 0,75 \\
\hline Novilhos(as) de 1 ano & 0,60 \\
\hline Bezerro(a) até 12 meses & 0,40 \\
\hline Bezerro(a) até 6 meses & 0,30 \\
\hline
\end{tabular}

Fonte: Adaptada de Antunes e Ries (2001).

Um bovino de $450 \mathrm{~kg}$ equivale a uma unidade animal correspondente a sua categoria ou espécie.

Quanto à rentabilidade, conforme Lima (2005) pode ser entendida como a relação percentual entre o lucro de um determinado período e o capital investido em um empreendimento.

E com relação ao desempenho produtivo, os índices de desempenho 
animal refletem em forma numérica o desempenho dos diversos parâmetros da exploração pecuária. A interpretação dos índices deve ser feita de forma conjunta com as características de produção empregadas na propriedade. O Quadro 1 evidencia alguns índices utilizados para a avaliação de desempenho da atividade pecuária.

\section{Quadro 1: Índices de desempenho animal}

\begin{tabular}{|c|c|c|}
\hline Índice & Fórmula & Descrição \\
\hline Índice de Fertilidade & $\frac{\mathrm{N}^{\circ} \text { de fêmeas prenhas }}{\mathrm{N}^{\circ} \text { de fềmeas em cobertura }}$ & $\begin{array}{l}\text { Mede o resultado das fêmeas em cobertura que ficaram } \\
\text { prenhas. }\end{array}$ \\
\hline Índice de Natalidade & $\begin{array}{c}\mathrm{N}^{\circ} \text { de bezerros nascidos } \\
\mathrm{N}^{\circ} \text { de fêmeas em cobertura }\end{array}$ & $\begin{array}{l}\text { Mede o resultado das fêmeas em cobertura que conse- } \\
\text { guiram parir bezerros vivos. }\end{array}$ \\
\hline Índice de Mortalidade & $\begin{array}{c}\mathrm{N}^{\circ} \text { de animais mortos } \\
\text { Rebanho total }\end{array}$ & $\begin{array}{l}\text { Apresenta a relação entre animais mortos por acidentes } \\
\text { e doenças em relação ao total do rebanho. }\end{array}$ \\
\hline $\begin{array}{l}\text { Índice de Mortalidade } \\
\text { Intra-Uterina }\end{array}$ & $\begin{array}{l}\mathrm{N}^{\circ} \text { de bezerros mortos } \\
\mathrm{N}^{\circ} \text { de fềmeas prenhas }\end{array}$ & $\begin{array}{l}\text { Representa as perdas de animais que foram abortados, } \\
\text { reabsorvidos ou natimortos. }\end{array}$ \\
\hline Índice de Desmame & $\frac{\mathrm{N}^{\circ} \text { de bezerros nascidos }}{\mathrm{N}^{\circ} \text { de fêmeas em cobertura }}$ & $\begin{array}{l}\text { Mede a relação entre a quantidade de bezerros desma- } \\
\text { mados e a quantidade de bezerros nascidos vivos. }\end{array}$ \\
\hline Indice de Descarte & $\begin{array}{c}\mathrm{N}^{\circ} \text { de animais descartados } \\
\text { Rebanho total }\end{array}$ & $\begin{array}{l}\text { Representa o percentual de animais descartados por } \\
\text { doenças, acidentes ou defeitos congênitos graves. }\end{array}$ \\
\hline İndice de Rendimento & $\begin{array}{c}\text { Peso da carcaça } \\
\text { Peso-vivo no abete }\end{array}$ & $\begin{array}{l}\text { Apresenta a relação entre o peso vivo do animal e o seu } \\
\text { peso de carcaça (peso morto). }\end{array}$ \\
\hline Indice de Desfrute & $\begin{array}{c}\text { Total abatido } \\
\text { Rebanho total } \\
\end{array}$ & $\begin{array}{l}\text { Mostra a capacidade do rebanho de gerar excedente para } \\
\text { venda sem descapitalizar a atividade produtiva. }\end{array}$ \\
\hline Indice de Densidade & $\frac{\mathrm{N}^{\circ} \text { de animais no psto }}{\text { Hectare pasto }}$ & $\begin{array}{l}\text { Apresenta a relação entre quantidade existente de } \\
\text { animais e a área ocupada pelos mesmos. }\end{array}$ \\
\hline $\begin{array}{l}\text { Indice de Crescimento } \\
\text { do Rebanho }\end{array}$ & $\frac{\mathrm{N}^{\circ} \text { de animais no final do ano }}{\mathrm{N}^{\circ} \text { de animais no inicio do ano }}$ & Identifica o aumento anual do rebanho. \\
\hline Ganho Médio Diário & $\frac{\text { Peso fnal - Peso inicial }}{\text { Número de dias da avaliação }}$ & $\begin{array}{l}\text { Mede o ganho médio diário em quilos ou em arrobas dos } \\
\text { animais, que estão sendo avaliados. }\end{array}$ \\
\hline $\begin{array}{l}\text { Indice de produção } \\
\text { pela área ocupada }\end{array}$ & $\frac{\text { Qtde de carne vendida }}{\text { Àrea utilizada }}$ & $\begin{array}{l}\text { Apresenta a relação entre a quantidade de carne vendi- } \\
\text { da em quilos e a área ocupada em hectares. }\end{array}$ \\
\hline
\end{tabular}

Fonte: Adaptado de Antunes e Ries (2001).

Para o cálculo dos índices apresentados no Quadro 1 é recomendado utilizar a quantidade em unidade padrão animal, possibilitando a geração de informações mais adequadas para a tomada de decisão. Os indicadores devem apresentar a situação atual mais próxima da realidade atual da organização, possibilitando ao gestor verificar se os objetivos e as estratégias pré-estabelecidos estão sendo alcançadas.

Andrade (2001) argumenta que a gestão da organização rural deve considerar o tamanho e volume das culturas; o rendimento das culturas e criações; a combinação e seleção das atividades; a produtividade da mão-de-obra e a eficiência das máquinas e equipamentos como variáveis para a definição de objetivos e estratégias organizacionais e produtivas. 


\subsection{Missão, Visão e Estratégia da Organização Rural Estudada}

De acordo com os responsáveis pela organização rural sua missão é: "Produzir gado bovino de corte para abate com qualidade, seguindo as especificações técnicas e ambientais, atendendo as necessidades dos clientes, funcionários e proprietários".

A propriedade possui a seguinte visão definida: "Ser conhecida como uma organização que produz gado de corte de alta qualidade e proporciona o retorno exigido por seus proprietários".

Para concretizar a visão mencionada, a organização rural estabelece a seguinte estratégia: "Aumentar o índice de produção por área ocupada e aumentar o preço médio de venda da produção comercializada".

Definida a estratégia são determinados os objetivos estratégicos de acordo com as quatro perspectivas do BSC para o conhecimento e envolvimento de todos os integrantes, elaborando para esse fim o mapa estratégico.

4.2 Mapa Estratégico e Indicadores para Avaliação de Desempenho da Organização Rural em Estudo

Identificadas a missão, a visão e a estratégia da organização rural em estudo é elaborado o mapa estratégico, conforme Figura 4, detalhado na seqüência. 


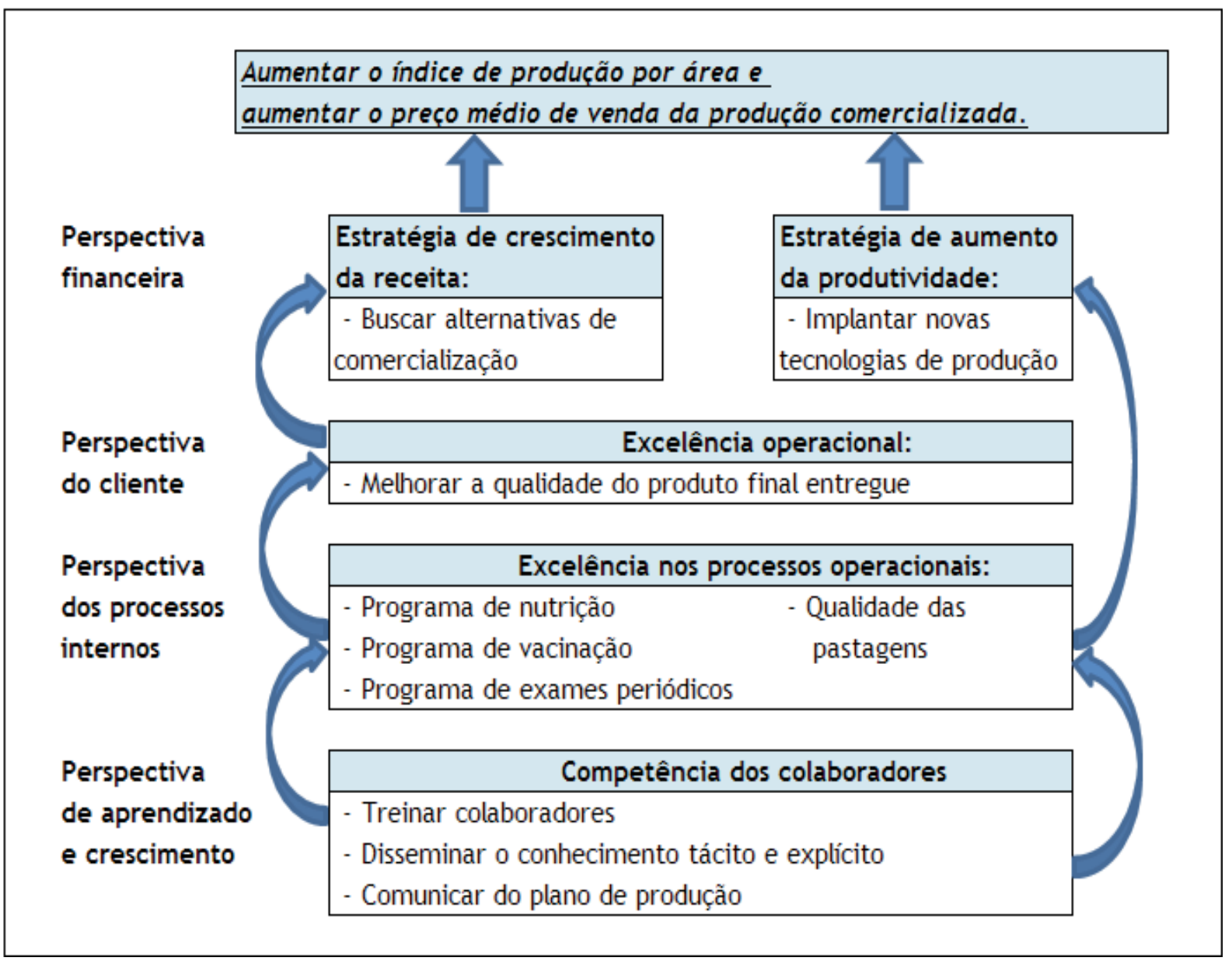

Figura 4: Mapa estratégico

Fonte: Elaborada pelos autores.

Para o cumprimento da estratégia da organização rural estudada, na perspectiva financeira foi definido como objetivos estratégicos, buscar alternativas de comercialização e implantar novas tecnologias de produção.

Os objetivos estratégicos da perspectiva financeira são atingidos se a organização melhorar a qualidade do produto, bem como aperfeiçoar seus processos produtivos, sendo estes os objetivos estratégicos definidos nas perspectivas do cliente e dos processos internos.

Para que a organização pesquisada consiga um animal com maior valor de comercialização e melhor produção por área, é necessário atingir os objetivos estratégicos determinados na perspectiva dos processos internos, ou seja, desenvolver e controlar os programas de nutrição, vacinação, exames periódicos e a qualidade das pastagens.

$\mathrm{Na}$ perspectiva de aprendizado e crescimento os objetivos estratégicos devem permitir a realização das outras três perspectivas, sendo necessário para isto, treinamento de todos os envolvidos no processo de produção, comunicação 
do plano de produção e disseminação do conhecimento tácito e explícito para a implementação do modelo de avaliação, bem como para a tomada de decisão para o cumprimento da estratégia organizacional.

O mapa estratégico proporciona a identificação das relações de causas e efeitos, conforme descrito anteriormente. Com isso, são determinados os indicadores, proporcionando avaliar a realização da estratégia e conseqüentemente da visão e da missão definidas pela organização, conforme Quadro 2.

Quadro 2: Objetivos estratégicos e indicadores

\begin{tabular}{|c|c|}
\hline Objetivos estratégicos & Indicadores \\
\hline \multicolumn{2}{|l|}{ Perspectiva financeira } \\
\hline $\begin{array}{l}\text { - Buscar alternativas de comercialização } \\
\text { - Implantar novas tecnologias de produção }\end{array}$ & $\begin{array}{l}\text { - Lucratividade } \\
\text { - Rentabilidade } \\
\text { - Custo por animal } \\
\text { - Animal por hectare } \\
\text { - Ganho de peso }\end{array}$ \\
\hline \multicolumn{2}{|l|}{ Perspectiva do cliente } \\
\hline $\begin{array}{l}\text { - Melhorar a qualidade do produto final } \\
\text { entregue }\end{array}$ & - indice de satisfação \\
\hline \multicolumn{2}{|l|}{ Perspectiva dos processos internos } \\
\hline $\begin{array}{l}\text { - Programa de nutrição } \\
\text { - Programa de vacinação } \\
\text { - Programa de exames periódicos } \\
\text { - Qualidade das pastagens }\end{array}$ & $\begin{array}{l}\text { - Índice de natalidade } \\
\text { - Índice de mortalidade } \\
\text { - Índice de descarte } \\
\text { - Índice de rendimento }\end{array}$ \\
\hline \multicolumn{2}{|c|}{ Perspectiva do aprendizado e crescimento } \\
\hline $\begin{array}{l}\text { - Treinamento } \\
\text { - Disseminação do conhecimento } \\
\text { - Comunicação do plano de produção }\end{array}$ & $\begin{array}{l}\text { - horas de treinamento } \\
\text { por colaborador } \\
\text { - \% de colaboradores } \\
\text { conhecedores do plano }\end{array}$ \\
\hline
\end{tabular}

Fonte: Elaborado pelos autores.

De acordo com as informações disponibilizadas no Quadro 2, nota-se que na perspectiva financeira, os indicadores lucratividade, rentabilidade, custo por animal, animal por hectare e ganho de peso, proporcionarão avaliar se as decisões estão gerando o retorno esperado.

Para avaliar se a qualidade do gado de corte está atendendo as exigências dos clientes, será elaborada uma pesquisa de satisfação.

$\mathrm{Na}$ perspectiva dos processos internos, os índices de natalidade, de mortalidade, de descarte e de rendimento avaliarão o efeito da estratégia de produção na qualidade o produto final e resultado das operações.

Para atingir os objetivos estratégicos definidos nas perspectivas financeira, do cliente e dos processos internos é necessário que os mesmos sejam conhecidos 
de todos, além de estarem preparados para executar tais objetivos, para isso é determinado os indicadores horas de treinamento e porcentagem de integrantes da organização conhecedores do plano.

Conhecido as relações de causas e efeitos que levam ao cumprimento da estratégia da organização, e determinado os indicadores que avaliarão se os objetivos estratégicos estão sendo atingidos, é elaborado um painel de desempenho, conforme Quadro 3, demonstrando os objetivos estratégicos, os resultados dos indicadores e as metas estabelecidas.

Quadro 3: Painel de avaliação de desempenho

\begin{tabular}{|c|c|c|c|}
\hline Objetivos estratégicos & Indicadores & Resultado & Metas \\
\hline \multicolumn{4}{|l|}{ Perspectiva financeira } \\
\hline $\begin{array}{l}\text { - Buscar alternativas de comercialização } \\
\text { - Implantar novas tecnologias de produção }\end{array}$ & $\begin{array}{l}\text { - Lucratividade } \\
\text { - Rentabilidade } \\
\text { - Custo por animal } \\
\text { - Animal por hectare } \\
\text { - Ganho de peso }\end{array}$ & $\begin{array}{l}9 \% \\
2 \% \\
144,49 \\
0,91 \\
5 \%\end{array}$ & $\begin{array}{l}>10 \% \\
>10 \% \\
<10 \% \\
>10 \% \\
>10 \%\end{array}$ \\
\hline \multicolumn{4}{|l|}{ Perspectiva do cliente } \\
\hline $\begin{array}{l}\text { - Melhorar a qualidade do produto final } \\
\text { entregue }\end{array}$ & - ìndice de satisfação & $\begin{array}{l}\text { não } \\
\text { medido }\end{array}$ & $90 \%$ \\
\hline \multicolumn{4}{|l|}{ Perspectiva dos processos internos } \\
\hline $\begin{array}{l}\text { - Programa de nutrição } \\
\text { - Programa de vacinação } \\
\text { - Programa de exames periódicos } \\
\text { - Qualidade das pastagens }\end{array}$ & $\begin{array}{l}\text { - Índice de natalidade } \\
\text { - Índice de mortalidade } \\
\text { - Índice de descarte } \\
\text { - Índice de rendimento }\end{array}$ & $\begin{array}{c}1 \% \\
0,01 \% \\
0 \% \\
178 \mathrm{Kg}\end{array}$ & $\begin{array}{l}>10 \% \\
<10 \% \\
<10 \% \\
>10 \%\end{array}$ \\
\hline \multicolumn{4}{|l|}{ Perspectiva do aprendizado e crescimento } \\
\hline $\begin{array}{l}\text { - Treinamento } \\
\text { - Disseminação do conhecimento } \\
\text { - Comunicação do plano de produção }\end{array}$ & $\begin{array}{l}\text { - horas de treinamento } \\
\text { por colaborador } \\
\text { - \% de colaboradores } \\
\text { conhecedores do plano }\end{array}$ & $\begin{array}{l}1 \mathrm{~h} \\
80 \%\end{array}$ & $\begin{array}{l}1 \mathrm{~h} \\
100 \%\end{array}$ \\
\hline
\end{tabular}

Fonte: Elaborado pelos autores.

De acordo com as informações evidenciadas no Quadro 3, verifica-se a situação atual do desempenho da organização rural em estudo. Conjetura-se que, de posse dos resultados dos indicadores, o conhecimento organizacional e individual deve ser compartilhado e utilizado para a tomada de decisão buscando informações internas e externas, determinando alternativas de possíveis soluções, avaliando as alternativas, escolhendo as alternativas para manter ou melhorar os resultados e determinando metas a serem atingidas para cada perspectiva do 
BSC.

Por fim, o resultado da implementação do modelo de avaliação Balanced Scorecard, de acordo com as premissas da gestão do conhecimento, permitiu aos gestores da organização rural conhecer a situação atual, identificar pontos de desvios e definir ações corretivas, buscando, com isso, atingir seus objetivos, estratégias, sua visão e, principalmente, cumprir a sua missão.

\section{Considerações Finais}

As organizações constantemente tomam decisões para manutenção ou melhoria de situações para a sua permanência e crescimento no mercado onde realizam suas atividades. É necessário a utilização de dados, informações e conhecimento para o processo decisório atingir os objetivos estabelecidos.

Nesse sentido, o trabalho buscou estudar a contribuição da gestão do conhecimento tácito e explícito acumulados pelas organizações, no processo de implementação do BSC e no processo decisório organizacional, para manter ou melhorar a situação evidenciada por seus indicadores.

Para a consecução do objetivo proposto, com base na literatura, o estudo buscou realçar o processo de gestão do conhecimento, o processo de avaliação de desempenho, o processo de tomada de decisão e o processo de implementação do Balanced Scorecard em uma organização rural.

O modelo de avaliação de desempenho BSC, utilizado no estudo, é uma ferramenta ou metodologia que traduz e dissemina a missão, a visão e a estratégia em um conjunto de indicadores agrupados em quatro perspectivas, sendo elas: financeira, clientes, processos internos e crescimento e aprendizagem.

Os resultados da avaliação do desempenho da organização permitiram aos gestores da organização rural conhecer a situação atual, identificar pontos de desvios e definir ações corretivas, buscando, com isso, atingir seus objetivos, estratégias, sua visão e, principalmente, cumprir a sua missão.

O macro processo de implementação e decisão elaborado para uma organização rural, foi demonstrado por um fluxograma contemplando os processos de gestão do conhecimento, processo de implementação do BSC e o processo de tomada de decisão. Por fim, conjetura-se que o fluxograma proposto permite que o conhecimento organizacional seja acumulado, disseminado e utilizado pela organização, e auxilia no processo de implementação do modelo de avaliação, dos indicadores e nas fases do processo de decisão, contribuindo para a contínua geração de conhecimento nas organizações.

Por fim, o resultado da implementação do modelo de avaliação Balanced Scorecard, de acordo com as premissas da gestão do conhecimento, permitiu aos gestores da organização rural conhecer a situação atual, identificar pontos 
de desvios e definir ações corretivas, buscando, com isso, atingir seus objetivos, estratégias, sua visão e, principalmente, cumprir a sua missão.

\section{Referências}

ANDRADE, J. G. Introdução à administração rural. Lavras: UFLA/FAEPE, 2001.

ANTUNIES, L. M.; REIS, L. R. Gerência agropecuária. 2. ed. Guaiba: Agropecuária, 2001.

ARAUJO, M. J. Fundamentos de agronegócios. 2. ed. São Paulo: Atlas, 2005. CERVO, A.; BERVIAN, A. Metodologia científica: para uso dos estudantes universitários. 4. ed. São Paulo: McGraw-Hill do Brasil, 1996.

DAVENPORT, H. T.; PRUSAK, L. Conhecimento empresarial: como as organizações gerenciam seu capital intelectual - métodos e aplicações práticas. 14. ed. Rio de Janeiro: Campus, 1998.

DUTRA, A.; Ensslin, S.R.; Ensslin, L.; Lima; M. V. A. A incorporação da dimensão integrativa nos processos de avaliação do desempenho organizacional: um estudo de caso. Revista Conteporânea de Contabilidade, Florianópolis, v.1, n 11, p. 109-136, jan/jun. 2009.

DUTRA, A. Metodologia para avaliar o desemepenho organizacional: revisão e proposta de uma abordagem multicritério.. Revista Conteporânea de Contabilidade, Florianópolis, v.1, n 02, p. 25-56, jan/jun. 2005.

EMBRAPA - Empresa Brasileira de Pesquisa Agropecuária. Desempenho produtivo nas fases de cria e recria em um sistema de produção de gado de corte no Brasil Central. Campo Grande: Embrapa Gado de Corte, 2005.

FIATES, G. G. S. Cultura organizacional: um fator determinante para a promoção da aprendizagem organizacional e da gestão do conhecimento. In: ANGELONI, M. T. (Org.) Gestão do conhecimento no Brasil: casos, experiências e práticas de empresas públicas. Rio de Janeiro: Qualitymark, 2008, p. 127-137.

FIGUEIREDO, S.; CAGGIANO, P. C. Controladoria: teoria e prática. 4. ed. São Paulo: Atlas, 2004.

GOULART, S. Gestão do conhecimento integrada à estratégia organizacional. In: ANGELONI, M. T. (Org.) Gestão do conhecimento no Brasil: casos, experiências e práticas de empresas públicas. Rio de Janeiro: Qualitymark, 2008, p. 25-34. 
HERRERO FILHO, E. Balanced scorecard e a gestão estratégica. Rio de Janeiro: Elsevier, 2005.

KAPLAN, R. S.; NORTON, D. P. A estratégia em ação: balanced scorecard. 5. ed. Rio de Janeiro: Campus, 1997.

. Using the balanced scorecard as a strategic management system. Harward Business Review, Boston, jan-fev. 1999.

. Organização orientada para a estratégia: como as empresas que adotam o Balanced Scorecard prosperam no novo ambiente de negócios. 2. ed. Rio de Janeiro: Campus, 2000.

. Kaplan e Norton na prática. Rio de Janeiro: Elsevier, 2004.

KARDEC, A.; ARCURI, R.; CABRAL, N. Gestão estratégica e avaliação de desempenho. 2. ed. Rio de Janeiro: Qualitymark, 2005.

KARDEC, A.; FLORES, J. F.; SEIXAS E. Gestão estratégica e indicadores e desempenho. Rio de Janeiro: Qualitymark, 2005.

LIMA, E. A. Avaliação de um sistema de gestão integrado de acordo com os preceitos da controladoria: estudo de caso. Trabalho de conclusão de curso. Centro Universitário da Fundação Educacional de Guaxupé. Guaxupé, 2009.

LIMA, N. C. Situações de rentabilidade na pecuária de corte da raça nelore no estado de São Paulo. Dissertação (Mestrado em Administração). Faculdade de Economia, Administração e Contabilidade da Universidade de São Paulo. São Paulo, 2005.

MIRANDA, L. C.; SILVA, J. D. G. Medição de desempenho. In: SHIMIDT, P. Controladoria agregando valor para a empresa. Porto Alegre: Bookman, 2002, p. 131-154.

MOSIMANN, C. P.; FISCHER, S. Controladoria: seu papel na administração de empresas. 2. ed. São Paulo: Atlas, 1999.

MUSSI, C. C.; ANGELONI, M. T. Compartilhamento do conhecimento no contexto de projetos de tecnologia da informação. In: ANGELONI, M. T. (Org.). Gestão do conhecimento no Brasil: casos, experiências e práticas de empresas públicas. Rio de Janeiro: Qualitymark, 2008, p. 61-73.

NASCIMENTO, S.; REINA, D. R. M.; GALLON, A. V.; ENSSLIN, S. R.; SOUZA, J. V. Proposição de uma metodologia baseada no BSC para suporte à gestão 
estratégica de uma transportadora de carga fracionada. RGO Revista de Gestão Organizacional, v. 1, n. 2, jul./dez. 2008.

NOKATA, I.; TAKEUCHI, H. Criação de conhecimento na empresa: como as empresas japonesas geram a dinâmica da inovação. Rio de Janeiro: Campus 1997.

NUINTIN, A. A. O desenvolvimento de indicadores do desempenho e da qualidade para o processo de produção: estudo de casos do processo de produção do café. Dissertação (Mestrado em Controladoria e Contabilidade). Faculdade de Economia, Administração e Contabilidade de Ribeirão Preto, Universidade de São Paulo. Ribeirão Preto, 2007.

OLIVEIRA, L. M; PEREZ JR., J. H; SILVA, C. A. S. Controladoria estratégica. 3. ed. São Paulo: Atlas, 2005.

PEREIRA, C. A. Avaliação de resultados e desempenho. In: CATELLI, A. (Org.). Controladoria: uma abordagem da gestão econômica GECON. 2. ed. São Paulo: Atlas, 2001, p.196-266.

PEREIRA, E. Controladoria, gestão empresarial e indicador de eficiência em agribusiness. In: MARION, J. C. (Coord). Contabilidade e controladoria em agribusiness. São Paulo: Atlas, 1996, p.134-152.

SANTOS, G. J.;MARION, J. C.; SEGATTI, S. Administração de custos na agropecuária. São Paulo: Atlas, 2002.

SANTOS, E. S.; PONTE, V. M. Modelo de decisão em gestão econômica. Caderno de Estudos, São Paulo, FIPECAFI, v. 10, n. 19, p. 43-56, set./dez. 1998.

SCHARF, E. R.; SORIANO-SIERRA, E. J. A gestão do conhecimento e o valor percebido: estratégia competitiva sustentável para a era do conhecimento. Revista de Gestão da Tecnologia e Sistemas de Informação, v. 5, n. 1, 2008, p. 87-108.

SCHMIDT, P.; SANTOS, J. L.; MARTINS, M. A. Avaliação de empresas: foco na análise de desempenho para o usuário interno - teoria e prática. São Paulo: Atlas, 2006.

SHIMIZU, T. Decisão nas organizações. 2. ed. São Paulo: Atlas, 2006.

TERRA, J. C. C. Gestão do conhecimento: o grande desafio empresarial - uma abordagem baseada no aprendizado e na criatividade. São Paulo: Negócio Editora, 2000.

YIN, R. K. Estudo de caso: planejamento e métodos. 3. ed. Porto Alegre: Book- 
man, 2005. 